\title{
HIV-1 Tat and cocaine mediated synaptopathy in cortical and midbrain neurons is prevented by the isoflavone Equol
}

\author{
Sarah J. Bertrand, Calvin Hu, Marina V. Aksenova, Charles F. Mactutus and \\ Rosemarie M. Booze*
}

Laboratory Program in Behavioral Neuroscience, Department of Psychology, University of South Carolina, Columbia, SC, USA

OPEN ACCESS

Edited by:

Venkata Subba Rao Atluri Florida International University, USA

Reviewed by: Jieliang Li,

Temple University, USA Santosh Kumar

University of Tennessee Health Science Center, USA Michael R. Nonnemacher,

Drexel University, USA

*Correspondence:

Rosemarie M. Booze,

Laboratory Program in Behavioral

Neuroscience, Department of Psychology, University of South Carolina, 1512 Pendleton Street. Barnwell College Building, Columbia, SC 29208, USA

booze@mailbox.sc.edu

Specialty section:

This article was submitted to

Virology,

a section of the journal

Frontiers in Microbiology

Received: 14 July 2015

Accepted: 17 August 2015

Published: 08 September 2015

Citation:

Bertrand SJ, Hu C, Aksenova MV, Mactutus CF and Booze RM (2015)

HIV-1 Tat and cocaine mediated synaptopathy in cortical and midbrain neurons is prevented by the isoflavone Equol.

Front. Microbiol. 6:894. doi: 10.3389/fmicb.2015.00894
Illicit drugs, such as cocaine, are known to increase the likelihood and severity of HIV1 associated neurocognitive disorders (HAND). In the current studies synaptic integrity was assessed following exposure to low concentrations of the HIV-1 viral protein Tat 1-86B, with or without cocaine, by quantifying filamentous actin (F-actin) rich structures (i.e., puncta and dendritic spines) on neuronal dendrites in vitro. In addition, the synapseprotective effects of either R-Equol (RE) or S-Equol (SE; derivatives of the soy isoflavone, daidzein) were determined. Individually, neither low concentrations of HIV-1 Tat (10 nM) nor low concentrations of cocaine $(1.6 \mu \mathrm{M})$ had any significant effect on F-actin puncta number; however, the same low concentrations of HIV-1 Tat + cocaine in combination significantly reduced dendritic synapses. This synaptic reduction was prevented by pre-treatment with either RE or SE, in an estrogen receptor beta dependent manner. In sum, targeted therapeutic intervention with SE may prevent HIV-1 + drug abuse synaptopathy, and thereby potentially influence the development of HAND.

\section{Keywords: soy isoflavone, F-actin, S-Equol, estrogen receptor, HAND}

\section{Introduction}

Cocaine abuse significantly increases the risk of HIV-1 transmission. HIV-1+ individuals that use cocaine progress from HIV-1 infection to AIDS more quickly (Baum et al., 2009), are more likely to develop neurocognitive disorders (Levine et al., 2006; Nath, 2010), and display an accelerated progression of HIV-1 associated neurocognitive disorders (HAND; Nath, 2010). Neurocognitive dysfunction and drug abuse are two of the most common factors for medication non-compliance in treatment of HIV-1 (Panos et al., 2014), and therefore HIV-1 positive drug abusers with neurocognitive disorders have a higher risk for disease progression, increased mortality rates, and a lower quality of life (Wisniewski et al., 2005; Cook et al., 2007; Baum et al., 2009; Doshi et al., 2012; Qian et al., 2014).

Effective combined anti-retroviral therapy (cART) suppresses viral replication. However, infected astrocytes and microglia may continue to release HIV-1 proteins (i.e., Tat), into the extracellular space (Nath, 2010; Desplats et al., 2013). The released HIV-1 Tat proteins may then interact with neurons to produce dysfunction (Moore et al., 2006; Chang et al., 2008; Gongvatana et al., 2011; Desplats et al., 2013; Ortega et al., 2015). Exposure to the HIV-1 Tat protein produces loss of F-actin prior to cell death (Bertrand et al., 2013, 2014). HIV-1 Tat protein increases actin 
depolymerization (Wu et al., 2004) and HIV-1 Tat protein alters NMDA receptor calcium currents via interactions with the actin cytoskeleton (Krogh et al., 2015). The HIV-1 Tat induced loss of F-actin may be a reversible process, mediated by stimulation of estrogen receptors (Bertrand et al., 2014). Thus, F-actin dysregulation may play a key role in HIV-1 induced synaptodendritic damage and synaptopathy.

Pre- and post-synaptic neuronal structures are rich in actin, a dynamic cytoskeletal protein (Zhang and Benson, 2001; Johnson and Ouimet, 2006; Sekino et al., 2007; Hotulainen et al., 2009). Subsequent to cellular signaling, globular actin (Gactin) is polymerized into filamentous actin (F-actin), resulting in a stable synaptic structure (Johnson and Ouimet, 2006; Sekino et al., 2007; Hotulainen et al., 2009). Stabilized synaptic structures are rich in F-actin and appear as punctate dendritic structures (Bertrand et al., 2014); these F-actin neuronal structures may be either protruding mature dendritic spines, early stages of developing dendritic spines (patches; Matus et al., 1982; Johnson and Ouimet, 2006; Sekino et al., 2007; Hotulainen et al., 2009), non-spiny or inhibitory synapses (Heller et al., 2012), or pre-synaptic structures (Halpain, 2003; Sankaranarayanan et al., 2003). Since F-actin puncta encompass a variety of synaptic structures (Halpain, 2003; Sankaranarayanan et al., 2003) decreased F-actin puncta indicates a synaptopathy in which synaptic response and connectivity is globally diminished.

HIV-1 transgenic rats have abnormally short and stubby dendritic spines (Roscoe et al., 2014). Similarly, tat protein transgenic mice show decreased spine density (Fitting et al., 2015). HIV-1 infected cells have significantly decreased spine density, spine length, spine area, and spine number in comparison to uninfected control cells (Kurapati et al., 2013) and increased HIV-1 cell death in combination with cocaine (Kurapati et al., 2014). Conversely, chronic cocaine exposure in rats increased the expression of F-actin (Kalivas, 2009) and increases dendritic spine density (Martin et al., 2011). Actively inhibiting the polymerization of G-actin into F-actin prevents spine morphological changes found in the nucleus accumbens of rats acutely treated with cocaine (Toda et al., 2010). Although it is clear that both HIV-1 Tat protein and cocaine alter dendritic spines, the combined effects of HIV-1 Tat and cocaine on F-actin containing synapses have not been investigated.

Phytoestrogens are naturally occurring compounds that are structurally similar to $17 \beta$-estradiol (Glazier and Bowman, 2001; Lephart et al., 2005). The soy-derived phytoestrogen daidzein prevents HIV-1 Tat induced neuronal apoptosis (Adams et al., 2012) and synaptodendritic injury caused by HIV-1 Tat (Bertrand et al., 2014). Daidzein is initially metabolized in the gut into dihydrodaidzein, which is further metabolized into either O-desmethylangolensin or cis/trans-isoflavan-4-ol (Lampe, 2009; Jackson et al., 2011). Finally, cis/trans-isoflavn-4-ol is processed into S-Equol (SE). Due to the chiral center at carbon 3, equol can exist in either the $\mathrm{S}$ or $\mathrm{R}$ conformation; however, only SE is produced by humans and animals (Setchell et al., 2005). Equol affects neuronal mitochondrial function (Yao et al., 2013) and hypothalamic neuronal expression (Patisaul et al., 2009) in vivo, suggesting that equol can cross the blood-brain barrier at physiological concentrations.

HIV-1+ cocaine abusers are more likely to display neurocognitive deficits relative to non-drug abusers (Levine et al., 2006; Nath, 2010); however, the mechanism producing these neurocognitive deficits is unclear. HIV-1 viral infection in the presence of cocaine has been shown to cause cell death in vitro (Kurapati et al., 2013, 2014). HIV-1 Tat protein + cocaine has been reported to produce enhanced levels of apoptosis (Kendall et al., 2005). In contrast, the effects of HIV-1 Tat proteins + cocaine on synapses are unknown. The present study uses the quantification of F-actin puncta, a marker of dendritic synapses, to evaluate the effects of HIV-1 Tat and cocaine. Additionally, we evaluated the estrogen receptor-mediated mechanisms of both SE and R-Equol neuroprotection. Our results suggest that HIV-1 Tat and cocaine together produce enhanced synaptodendritic injury, resulting in a synaptopathy that may contribute to the increased incidence of neurocognitive disorders in HIV-1+ cocaine users. S- and R-Equol (RE) treatment may prevent this synaptopathy via specific estrogen receptors.

\section{Materials and Methods}

\section{Ethics Statement}

Experiments were in accordance with NIH Guidelines. The Institutional Animal Care and Use Committee at the University of South Carolina (assurance number: A3049-01) reviewed and approved all animal usage.

\section{Primary Neuronal Cell Culture}

Cortical and midbrain regions were dissected from gestational day 18 Sprague-Dawley rat fetuses (Harlan Laboratories, Indianapolis, IN, USA) as previously described (Aksenova et al., 2006, 2009; Bertrand et al., 2011; for protocol see Li et al., 2015). Following dissection, brain tissue was incubated in a solution of $2 \mathrm{mg} / \mathrm{ml}$ trypsin in Hank's balanced salt solution (HBSS) buffered with $10 \mathrm{mM}$ HEPES (GIBCO Life Technologies, Grand Island, NY, USA) for $10 \mathrm{~min}$. Tissue was rinsed with fresh HBSS three times and then exposed to soybean trypsin inhibitor (1 $\mathrm{mg} / \mathrm{ml}$ in HBSS) for $2 \mathrm{~min}$. Tissue was washed three times with HBSS following trypsin inhibitor treatment. For cytomorphological studies, cells were distributed to 12 well glassbottom dishes and $35 \mathrm{~mm}$ dishes (MatTek Corporation, Ashland, MA, USA) coated with poly-L-lysine following dissociation by trituration. In order to observe distinct second order branching patterns, a low plating density was used (120-140 cells $/ \mathrm{mm}^{2}$ ). Initial plating media contained Dulbecco's modified Eagle's medium/Ham's nutrient mixture F-12 (DMEM/F12; GIBCO) supplemented with $100 \mathrm{ml} / \mathrm{L}$ fetal bovine serum (Sigma Chemicals, St. Louis, MO, USA). DMEM/F12 and fetal serum were removed and replaced with an equal amount of serumfree Neurobasal medium after $24 \mathrm{~h}$. Neurobasal medium had no phenol red and was supplemented with $2 \% \mathrm{v} / \mathrm{v}$ B-27, $2 \mathrm{mM}$ GlutaMAX supplement and $0.5 \% \mathrm{w} / \mathrm{v} \mathrm{D}-(1)$ glucose (all ingredients from GIBCO). Cultures were maintained at $37^{\circ} \mathrm{C}$ 
in a $5 \% \mathrm{CO}_{2} / 95 \%$ room air-humidified incubator at all times. Fresh Neurobasal medium was supplemented at weekly intervals. Midbrain cultures used for experiments were 21-30 days in vitro (DIV), cortical cultures were used for experiments at 14-21 DIV, cell cultures from both regions were $>85-90 \%$ neuronal as determined by MAP-2/GFAP/NucBlue fluorescent staining.

\section{Experimental Drug Treatments}

Recombinant Tat 1-86B (LAI/Bru strain of HIV-1 clade B, GenBank accession no. K02013; Diatheva, Fano, Italy) was added to the serum free growth media ( 10 or $50 \mathrm{nM}$ final concentration). In experiments where cocaine was included, freshly prepared cocaine solution (1.6 $\mu \mathrm{M}$ final concentration) was added to the serum free grown media concurrently with HIV-1 Tat $1-86 \mathrm{~B}$ treatment. The $1.6 \mu \mathrm{M}$ concentration of cocaine in the cultures reflects levels found in the arterial blood supply to the brain following IV cocaine administration in humans (Evans et al., 1996) and rats (Mactutus et al., 1994; Booze et al., 1997), thus representing a physiologically relevant concentration of cocaine. This cocaine concentration has been used in our previous studies (Kendall et al., 2005; Aksenov et al., 2006, 2008), and is well below the neurotoxic levels of cocaine (100 $\mu \mathrm{M}$; Bennett et al., 1993). The low concentration of S- and RE (33 nM), as well as the mid-range concentration of S- and RE (50 nM) used in these studies, are similar to plasma concentrations observed in humans following supplementation ( 8 and $12 \mathrm{ng} / \mathrm{ml}$, respectively; Jackson et al., 2011). Control cultures were treated with an equivalent volume of vehicle. Cultures were incubated with either $50 \mathrm{nM} \mathrm{HIV}-1$ Tat, $10 \mathrm{nM}$ HIV-1 Tat, $1.6 \mu \mathrm{M}$ cocaine, or HIV-1 Tat(10 nM) + cocaine $(1.6 \mu \mathrm{M})$ for $24 \mathrm{~h}$ prior to fixation.

Cortical and midbrain cell cultures were treated with either SE (final concentration 33 or $50 \mathrm{nM}$; $\geq 98.5 \%$ purity; Cayman Chemical, Ann Arbor, MI, USA), RE (final concentration 33 or $50 \mathrm{nM}$; $\geq 98.5 \%$ purity; Cayman Chemical Ann Arbor, MI, USA), or tamoxifen (TMX; selective estrogen receptor antagonist; final concentration $100 \mathrm{nM}$; TMX citrate; Tocris Bioscience, Ellisville, MD). For the neuroprotection studies, cells were treated with either SE or RE (33 or $50 \mathrm{nM}$ ) for $24 \mathrm{~h}$ prior to treatment with either $50 \mathrm{nM}$ HIV-1 Tat or $10 \mathrm{nM} \mathrm{HIV-1}$ Tat $+1.6 \mu \mathrm{M}$ cocaine. In order to determine which estrogenic receptors were necessary for SE and RE neuroprotection, cells were treated with TMX for $1 \mathrm{~h}$ prior to treatment with either SE (50 nM), RE (50 nM), 4-[2-Phenyl-5,7-bis(trifluoromethyl)pyrazolo[1,5a]pyrmidin-3-yl)phenol (PHTPP) estrogen receptor beta $(\mathrm{ER} \beta)$ antagonist, final concentration $100 \mathrm{nM}$ (Tocris Bioscience, Ellisville, MD, USA); 1,3-Bis(4-hydroxyphenyl)4-methyl-5-[4-(2-piperidinylethoxy)phenol]-1H-pyrazole

dihydrochloride (MPP) estrogen receptor alpha antagonist; final concentration $100 \mathrm{nM}$ (Tocris Bioscience, Ellisville, MD, USA), or $\left(3 \mathrm{a} S^{*}, 4 R^{*}, 9 \mathrm{~b} R^{*}\right)$-4-(6-Bromo-1,3-benzodioxol-5yl)-3a,4,5,9b-3H-cyclopenta[c]quinoline (G15) membrane estrogen receptor antagonist, final concentration $100 \mathrm{nM}$ (Tocris Bioscience, Ellisville, MD, USA). TMX, PHTPP, G15, $\mathrm{SE}$, and RE were initially dissolved in DMSO and then diluted in PBS prior to treatment. MPP was initially dissolved in distilled water, and diluted immediately prior to treatment. For neuroprotection studies, cells were treated with either SE or RE (33 or $50 \mathrm{nM}$ ) for $24 \mathrm{~h}$ prior to treatment with $50 \mathrm{nM}$ Tat or $10 \mathrm{nM}$ Tat and $1.6 \mu \mathrm{M}$ cocaine. In order to determine which of the specific estrogen receptor subtypes might underlie $\mathrm{SE}$ and RE neuroprotection, cells were treated with TMX, PHTPP, MPP, or G15 for $1 \mathrm{~h}$ prior to treatment with SE or RE $(50 \mathrm{nM})$.

\section{Fluorescent Staining and Immunocytochemistry}

A previously described method (Bertrand et al., 2013; for detailed protocol see $\mathrm{Li}$ et al., 2015) for F-actin staining was used to visualize F-actin puncta localized on neuronal dendrites. Briefly, primary neuronal cultures were fixed using $4 \%$ paraformaldehyde and permeabilized with $0.1 \%$ Triton X-100. Cells were incubated with the F-actin specific probe, phalloidin (1:40; AlexaFluor 488), for 20 min (Invitrogen Life Technologies, Grand Island, NY, USA).

Following staining for F-actin, cultures were treated with $10 \%$ normal horse serum in PBS for $2 \mathrm{~h}$. Neurons were co-labeled with chicken polyclonal anti-MAP2 antibodies (1:1000; Abcam, Cambridge, MA, USA). Goat anti-chicken IgG conjugated with Alexa Red 594 (1:500; Invitrogen Life Technologies, Grand Island, NY, USA) was used as a secondary antibody to identify MAP2-positive dendrites. NucBlue (Molecular Probes Life Technologies, Grand Island, NY, USA), a Hoescht dye, was added directly to the cultures to identify cell nuclei (Bertrand et al., 2014).

A Nikon Eclipse TE2000-E inverted fluorescent microscope (20X objective, $1600 \times 1200 \mathrm{px}$ image size, $0.17 \mu \mathrm{m} / \mathrm{px}$ image resolution at $1 \mathrm{X}$ zoom) and a high resolution CCD camera was used to obtain images of neurons co-labeled with F-actin/MAP-2/NucBlue. The NIS-Elements software package (Nikon Instruments, Melville, NY, USA) was used to analyze 35 separate neurons per culture well. All imaged neurons had clearly identifiable complete dendritic arbors and normal nuclear morphology. F-actin puncta were identified in several (3-4) second order dendritic segments $(15-75 \mu \mathrm{m})$ for each neuron. For inclusion, dendrites were required to have continuous MAP2 positive immunofluorescence co-localized with Phalloidin staining. Phalloidin-labeled structures included fine filopodia, spine protrusions, and patches. Growth cones (F-actin rich structures at the distal end of dendrites) were excluded (Bertrand et al., 2013).

F-actin puncta were quantified as previously described (Bertrand et al., 2013, 2014). Briefly, background fluorescence from the 488 (green phalloidin labeled F-actin) channel was subtracted, identified as low fluorescence of the non-synaptic dendritic shaft (20-50 au). Bright F-actin rich structures on the dendrite (fine filopodia, spine protrusions, and patches) were manually counted. The number of F-actin puncta per $10 \mu \mathrm{m}$ of dendrite was reported by two trained independent observers. These investigators, blinded to experimental treatment, quantified puncta from identically processed 
images, with a very high correlation $\left(r^{2}=0.90\right)$, indicating that the bright green F-actin puncta on dendrites were readily identified.

\section{Statistical Analysis}

Statistical comparisons were made using ANOVA techniques, and Tukey's multiple comparison tests were used to determine specific treatment effects. Pearson's product-moment correlation coefficient was calculated to verify inter-rater reliability. Comparisons and correlations were calculated using SPSS version 22 (IBM Corporation, Armonk, NY, USA). Data represents mean values \pm SEM. Significant differences were set at $p \leq 0.05$.

\section{Results}

\section{S-Equol and R-Equol Prevent HIV-1 Tat Induced Synapse Loss}

Midbrain neurons were pre-treated with either RE (33 or $50 \mathrm{nM}$ ) or SE (33 or $50 \mathrm{nM}$ ) for $24 \mathrm{~h}$ prior to $50 \mathrm{nM} \mathrm{HIV-1}$ Tat (Figure 1). There was a significant main effect of treatment $F(1,22)=9.4, p \leq 0.001$, with $50 \mathrm{nM}$ HIV-1 Tat producing a significant reduction in F-actin puncta $(p \leq 0.001)$. Pretreatment with $50 \mathrm{nM} \mathrm{RE}(p \leq 0.01)$, but not $33 \mathrm{nM} \mathrm{RE}$, prevented significant loss of F-actin puncta following $50 \mathrm{nM}$ HIV-1 Tat (Figure 1B). Pre-treatment with either $33 \mathrm{nM}$ SE $(p \leq 0.05)$ or $50 \mathrm{nM} \mathrm{SE}(p \leq 0.001)$ prevented HIV-1 Tat induced loss of F-actin puncta (Figure 1C). RE and SE treatment alone did not produce either significant loss or proliferation of F-actin puncta (Figures 1B,C). RE or SE pre-treated HIV-1 Tat $(50 \mathrm{nM})$ neurons were not statistically different from vehicletreated neurons.

\section{S-Equol and R-Equol Act Through an Estrogen Mediated Mechanism to Prevent HIV-1 Tat Induced Synapse Loss}

The neuroprotective mechanisms of $\mathrm{RE}$ and $\mathrm{SE}$ in midbrain neurons against HIV-1 Tat induced synapse loss were determined by pre-treatment with TMX, a potent estrogen receptor antagonist. TMX was added to the cultures $1 \mathrm{~h}$ prior to the addition of either SE or RE. Cultures were then incubated with HIV-1 Tat 1-86 (50 nM) for $24 \mathrm{~h}$. Pre-treatment with TMX prior to $\mathrm{SE}(p \leq 0.02)$ and RE $(p \leq 0.02)$ resulted in significant loss of F-actin puncta relative to control cultures. These F-actin losses were not significantly different from cultures treated with HIV-1 Tat $(50 \mathrm{nM}$ ) alone, suggesting that RE and SE act through an ER dependent mechanism (Figure 1D).

\section{HIV-1 Tat and Cocaine Interact to Produce Synaptopathy in Midbrain and Cortical Neurons}

In order to examine the effects of HIV-1 Tat and cocaine on F-actin puncta, a low dose of HIV-1 Tat 1-86 (10 nM) and a physiologically relevant dose of cocaine $(1.6 \mu \mathrm{M})$ were

A

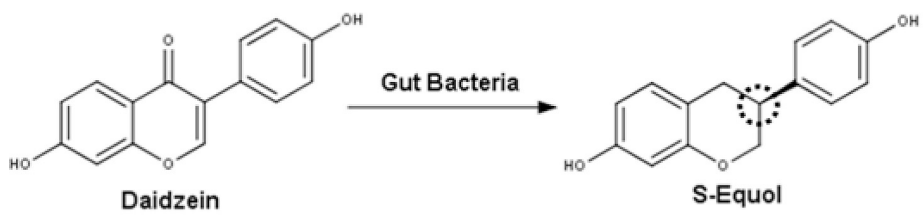

B

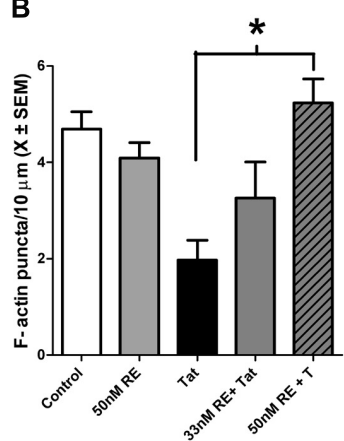

C

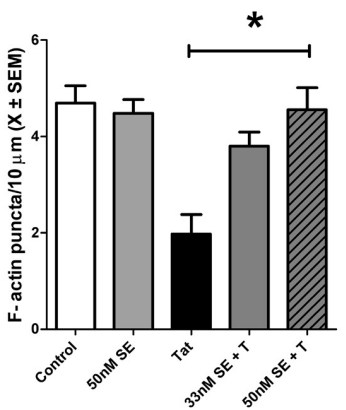

D

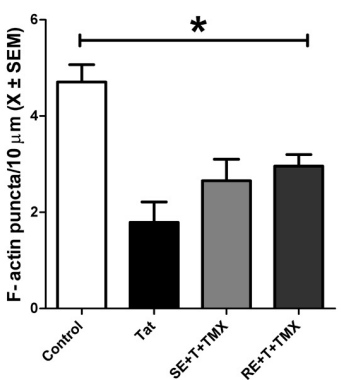

FIGURE 1 | R-Equol (RE) and S-Equol (SE) prevented synaptic loss induced by HIV-1 Tat (50 $\mathrm{nM}$ ) via an estrogen receptor mediated mechanism. (A) Conversion of the soy isoflavone daidzein to SE. The dotted circle identifies a chiral center on carbon 3 wherein a conformational change produces RE. However, only SE may be produced by mammalian gut bacteria. (B) A moderate concentration of RE (50 nM), but not a low concentration (33 nM), prevented significant F-actin puncta loss induced by HIV-1 Tat (50 nM; $p \leq 0.01)$. (C) Both the low $(33 \mathrm{nM})$ and moderate $(50 \mathrm{nM})$ concentrations of SE prevented HIV-1 Tat induced F-actin puncta loss $(p \leq 0.05$ and $p \leq 0.001$, respectively). (D) $1 \mathrm{~h}$ pre-treatment with TMX (100 nM) blocked the protective effects of RE and SE (50 nM) against HIV-1 Tat (50 nM) in midbrain neurons. Mean \pm SEM, ${ }^{*} p \leq 0.05$ compared to HIV-1 Tat treatment. 
A

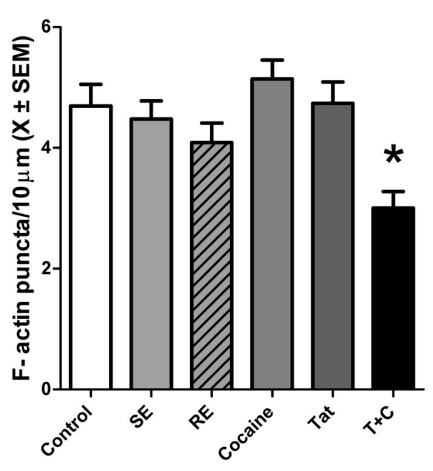

C

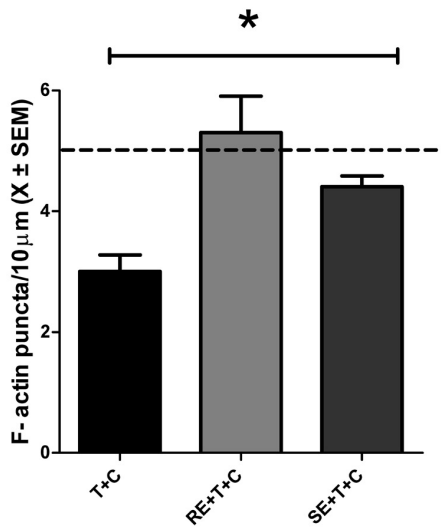

E

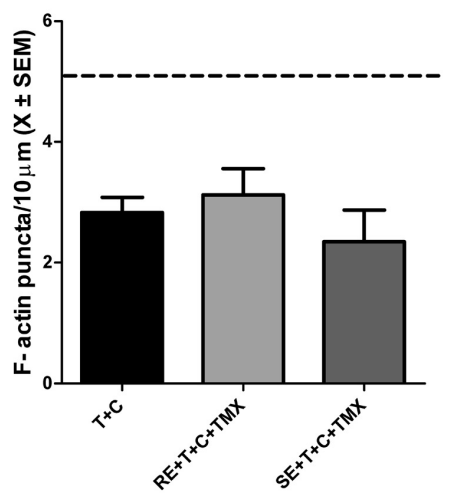

B

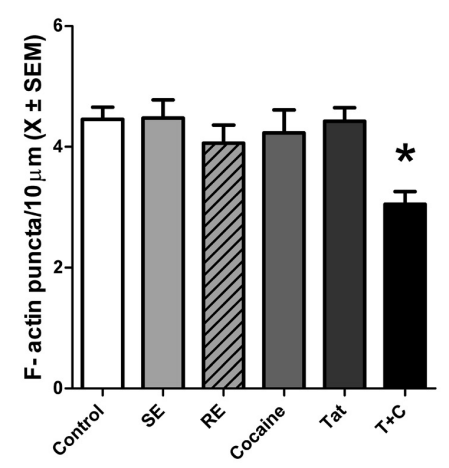

D

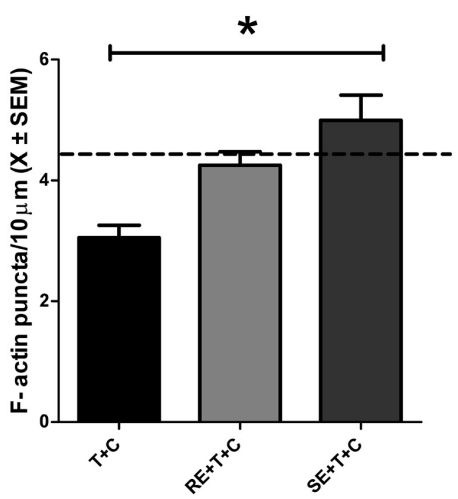

$\mathbf{F}$

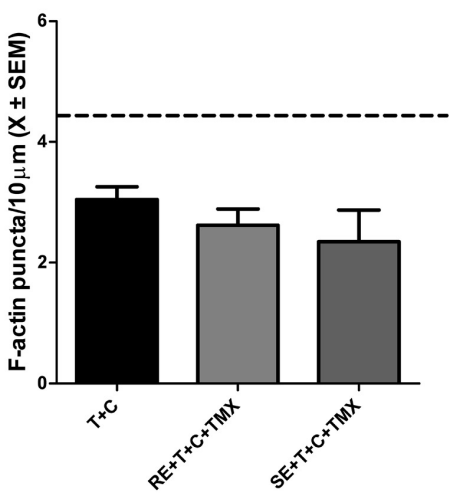

FIGURE 2 | HIV-1 Tat $(10 \mathrm{nM})$ + cocaine $(1.6 \mu \mathrm{M})$ treatment produced significant synaptic loss in midbrain and cortical neurons, which was prevented by pre-treatment with either RE or SE. (A) Treatment with either SE, RE, HIV-1 Tat, or cocaine does not significantly alter the density of dendritic F-actin puncta compared to controls in midbrain neurons. Treatment with HIV-1 Tat + cocaine produced significant loss of F-actin puncta $(p \leq 0.05)$. (B) Treatment with either SE, RE, HIV-1 Tat, or cocaine does not significantly alter the density of dendritic F-actin puncta compared to controls in cortical neurons. Treatment with HIV-1 Tat + cocaine produced significant loss of F-actin puncta $(p \leq 0.05)$. (C) Pre-treatment with either RE or SE (50 nM) prevented dendritic F-actin puncta loss caused by HIV-1 Tat + cocaine treatments in midbrain neurons. Dendrites from pre-treated neurons are not significantly different from vehicle-treated controls (mean values, dotted line). (D) Pre-treatment with either RE or SE (50 nM) prevents HIV-1Tat + cocaine induced loss of dendritic F-actin puncta $(p \leq 0.001)$ in cortical neurons. Dendrites from pre-treated neurons are not significantly different from vehicle-treated controls (mean values, dotted line). (E) Pre-treatment of midbrain neurons with TMX (100 nM) for $1 \mathrm{~h}$ prior to either RE or SE prevented the protective effects of RE and SE, suggesting an estrogen receptor mediated mechanism. Vehicle-treated control mean values are represented by dotted line. (F) Pre-treatment of cortical neurons with TMX (100 nM) for $1 \mathrm{~h}$ prior to either RE or SE prevented the protective effects of RE and SE, suggesting an estrogen receptor mediated mechanism. Control mean value represented by dotted line. Mean \pm SEM, ${ }^{*} p \leq 0.05$ compared either to vehicle-treated controls (A,B) or HIV-1 Tat + cocaine (C,D).

simultaneously added to the cultures and incubated for $24 \mathrm{~h}$. As shown in Figures $\mathbf{2 A , B}$, there was a significant effect of HIV-1 Tat + cocaine $F(1,123)=16.4,(p \leq 0.001)$ but no significant effect of either HIV-1 Tat or cocaine individually on dendritic F-actin puncta. Neurons cultured from fetal cortical and midbrain regions responded to HIV-1 Tat + cocaine similarly, as there were no significant differences between the brain region cultured $F(1,123)=3.4, p>0.05$. 


\section{S-Equol and R-Equol Prevent Interactive HIV-1 Tat + Cocaine Synaptopathy}

Cortical and midbrain neurons were pre-treated with either $50 \mathrm{nM}$ RE or SE for $24 \mathrm{~h}$ prior to HIV-1 Tat (10 nM) + cocaine $(1.6 \mu \mathrm{M})$. There was a significant main effect of treatment $F(5,123)=7.6, p \leq 0.001$ (Figures 2C,D), but not a significant effect of brain region $(p>0.05)$. Using a Tukey post hoc analysis it was determined that HIV-1Tat + cocaine neurons pretreated with either RE or SE had significantly more dendritic F-actin puncta relative to HIV-1 Tat + cocaine treated neurons $(p \leq 0.001)$. The number of puncta on RE and SE pre-treated neurons and were not significantly different from vehicle-treated controls.

\section{S-Equol and R-Equol Prevent HIV-1 Tat + Cocaine Induced Synaptopathy via an ER $\beta$ Mechanism}

Primary cortical and midbrain cultures were treated with TMX, an estrogen receptor antagonist, for $1 \mathrm{~h}$ prior to treatment with $\mathrm{RE}$ or SE. Following a $24 \mathrm{~h}$ incubation with HIV-1 Tat + cocaine, F-actin puncta were assessed. TMX pre-treatment prevented both $\mathrm{RE}$ and SE mediated synaptic protection following HIV-1 Tat + cocaine $(p \leq 0.01$; Figures $2 \mathrm{E}, \mathbf{F})$.

Cortical neurons were treated with one of three selective ER subtype antagonists, MPP (ER $\alpha)$, PHTPP (ER $\beta)$, or G15 (GPR30) for $1 \mathrm{~h}$ prior to treatment with $\mathrm{RE}$ or $\mathrm{SE}$ in order to identify the specific ER subtype required for equol-mediated synaptic protection following HIV-1 Tat + cocaine (Figures 3A,B). There was a significant main effect of antagonist treatment $F(3,134)=11.2, p \leq 0.001$. Further analysis revealed that both the MPP, as well as the G15, treated dendrites were not significantly different from vehicle-treated controls $(p>0.05)$; however, PHTPP-treated dendrites had a significant loss of F-actin puncta when compared to controls $(p \leq 0.05)$ and were not significantly different from HIV-1 Tat + cocaine treated dendtrites $(p>0.05)$. More specifically, only the ER $\beta$ antagonist PHTPP significantly prevented RE or SE mediated synaptic protection $(p \leq 0.001)$, indicative of an ER $\beta$ dependent mechanism. Examination of either vehicle (Figure 3C), HIV-1 Tat (10 nM; Figure 3G), cocaine (Figure 3H), or SE (Figure 3E)/RE (Figure 3F) pre-treated neurons found robust staining of dendrites with Phalloidin/F-actin (green) puncta and MAP-2 (blue) dendrites. These neurons exhibited complex dendritic branching patterns and an extensive fine dendritic network. In contrast, examination of PHTPP pretreated SE/HIV-1 Tat + cocaine treated (Figure 3I), PHTPP pre-treated RE/HIV-1 Tat + cocaine treated (Figure 3J), and HIV-1 Tat + cocaine treated (Figure 3D) neurons found reduced dendritic branching, diminished Phalloidin staining, and dendritic fragmentation.

\section{Discussion}

Neurocognitive deficits are more prevalent among HIV-1+ positive drug users (Nath, 2002; Levine et al., 2006; Devlin et al., 2012; Weber et al., 2013). Cocaine is one of the most commonly abused drugs in HIV-1+ individuals (Cook et al., 2007; Korthuis et al., 2008), and has been shown to potentiate neuronal death caused by HIV-1 proteins in vitro (Kendall et al., 2005; Aksenov et al., 2006). Although neuronal cell death is seen in HIV-1 (Li et al., 2005; Mattson et al., 2005), synaptic dysfunction and loss are more predictive of neurocognitive status (Ellis et al., 2007). We found (1) HIV1 Tat + cocaine exposure resulted in a significant reduction in F-actin rich puncta/synapses, relative to either HIV-1 Tat or cocaine alone, (2) pre-treatment with either RE or SE prevented the HIV-1 Tat + cocaine induced puncta/synaptic loss, and (3) RE and SE provided synaptic protection from HIV1 Tat + cocaine exposure via an ER $\beta$ dependent mechanism. These findings suggest that early treatment with RE or SE may prevent the synaptopathy caused by HIV-1 and cocaine abuse.

Cocaine potentiated the effects of HIV-1 Tat at doses in which HIV-1 Tat alone was not damaging to synaptic structures. The dose of HIV-1 Tat was fourfold lower than concentrations previously shown to cause neuronal death in similar neuronal cell cultures (Kendall et al., 2005). The dose of cocaine reflected physiological arterial levels observed in IV cocaine users (Evans et al., 1996) and rats (Mactutus et al., 1994; Booze et al., 1997); well below the cocaine concentration known to produce neuronal death in vitro (Bennett et al., 1993; Nassogne et al., 1995). However, low doses of HIV-1 Tat + cocaine produced synaptic loss at an early time point $(24 \mathrm{~h})$ prior to the time previously reported for neuronal death (48 h; Bertrand et al., 2014). HIV-1 Tat (Wallace et al., 2006; Ferris et al., 2009; Midde et al., 2013) and cocaine (Ritz and Kuhar, 1993) both inhibit dopamine transporter (DAT) function, increase oxidative stress (Aksenov et al., 2006; Fitting et al., 2015), and thereby may cause depolymerization of F-actin and a subsequent reduction of F-actin rich puncta/synapses.

S-Equol is the active metabolite of the soy derived phytoestrogen daidzein (Setchell and Cassidy, 1999; Jackson et al., 2011), and daidzein has been proposed to be responsible for the cognitive health benefits of soy products (Setchell and Cassidy, 1999; Lampe, 2009; Jackson et al., 2011). Daidzein is metabolized into SE via two distinct steps by various bacteria found in the gut of animals and humans (Setchell et al., 2005; Jackson et al., 2011). In humans, daidzein supplementation results in plasma concentrations of $8-20 \mathrm{ng} / \mathrm{ml} \mathrm{S}$-equol (see review: Jackson et al., 2011). A low concentration of S- and RE $(33 \mathrm{nM})$ as well as the mid-range concentration of equol $(50 \mathrm{nM})$ are equivalent to plasma concentrations observed in humans following supplementation ( 8 and $12 \mathrm{ng} / \mathrm{ml}$, respectively); hence, these doses were used to evaluate potential synaptic protection. Both enantiomers achieve full synaptic protection at physiologically relevant concentrations that were $20 \mathrm{x}$ lower than that of daidzein required for full protection (Bertrand et al., 2014). Neurons pre-treated with daidzein and exposed to a neurotoxic concentration of HIV-1 Tat protein were able to not only maintain, but also restore lost synapses (Bertrand et al., 2014); together, these results and those in the present study, suggest that SE may be a potent aid in the prevention and restoration of synaptic loss. 
A

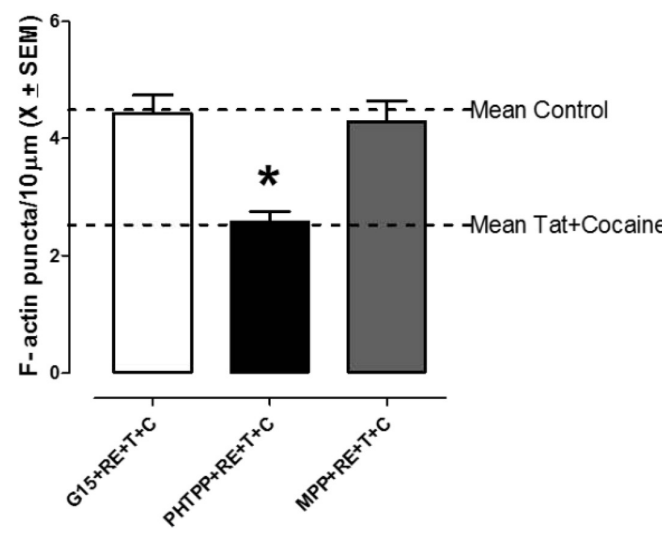

B

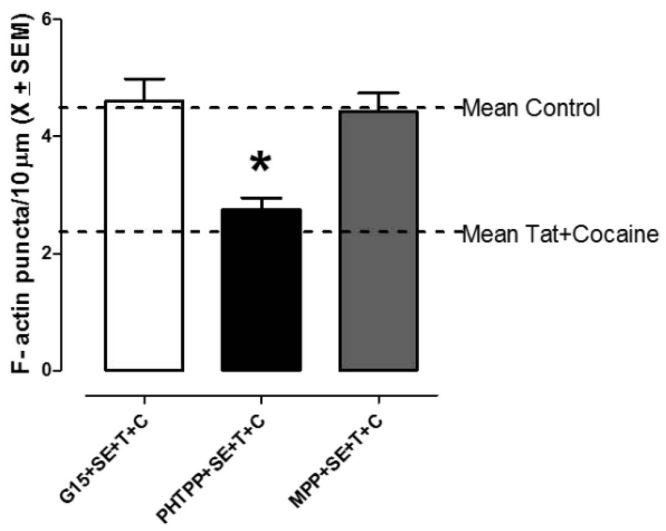

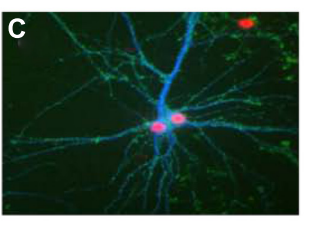
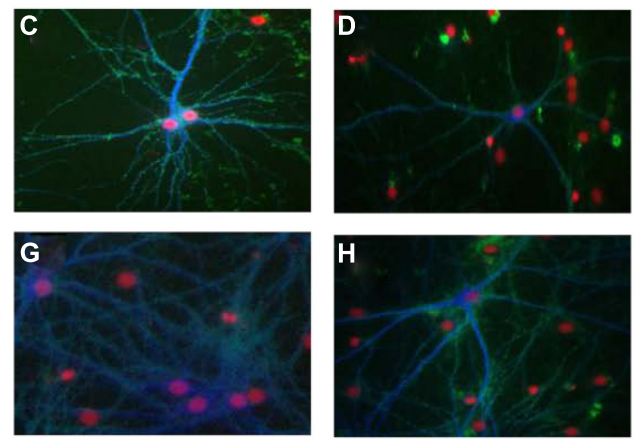
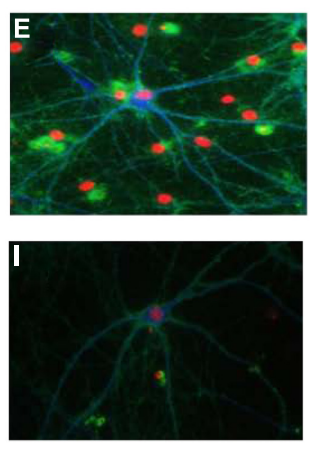
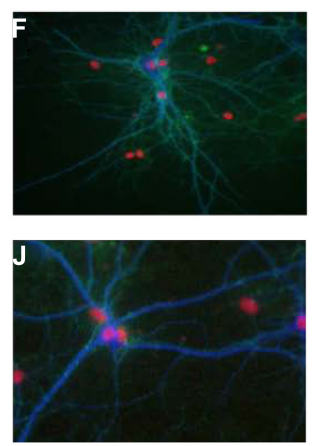

FIGURE 3 | R-Equol and SE prevented HIV-1 Tat + cocaine synaptic loss via a selective estrogen receptor (ER $\beta$ ) dependent mechanism. Cortical neurons were pre-treated for $1 \mathrm{~h}$ with either MPP (ER $\alpha)$, PHTPP (ER $\beta)$, or G15 (GPR30) prior to treatment with either RE (A) or SE (B) to identify which specific ER subtype was necessary for equol-mediated synaptic protection from HIV-1 Tat + cocaine. We found that pre-treatment with PHTPP (ER $\beta$ ) inhibited both the RE (panel A) and SE (panel B) induced synaptic protection in HIV-1 Tat + cocaine treated cortical neurons. (A) HIV-1 Tat + cocaine exposed neurons pre-treated with either MPP or G15, and subsequently RE, had normal levels of dendritic F-actin puncta (i.e., not significantly different from vehicle-treated controls, $p>0.05$ ). In contrast, PHTPP-treated neurons had a significant loss of dendritic F-actin puncta compared to controls $(p \leq 0.05)$ and were not significantly different from HIV-1 Tat + cocaine treated dendrites $(p>0.05)$, indicating that PHTPP inhibited RE-induced synaptic protection. Mean \pm SEM, * $p \leq 0.05$. (B) HIV-1 Tat + cocaine exposed neurons pre-treated with either MPP or G15, and subsequently SE, had normal levels of dendritic F-actin puncta (i.e., not significantly different from vehicle-treated controls, $p>0.05)$. In contrast, PHTPP-treated neurons had a significant loss of dendritic F-actin puncta compared to controls ( $p \leq 0.05)$ and were not significantly different from HIV-1 Tat + cocaine treated dendrites $(p>0.05)$, indicating that PHTPP inhibited SE-induced synaptic protection. Mean \pm SEM, ${ }^{*} p \leq 0.05$. (C-J) The ER $\beta$ antagonist PHTPP significantly blocked equol-mediated protection from HIV-1 Tat + cocaine in cortical neurons. PHTPP pre-treated, $\mathrm{SE}(\mathbf{I}) / \mathrm{RE}(\mathbf{J})$ treated, neurons lacked a fine dendritic network and had reduced dendritic branching, similar characteristics to those in non pre-treated HIV-1Tat + cocaine neurons (D). In contrast, vehicle (C), HIV-1 Tat (10 nM; G), cocaine (H), and SE(E)/RE(F) treated neurons had robust dendrites with complex branching patterns and a lack of aberrant morphology such as bundling or beading. Phalloidin/F-actin(green) and MAP-2 (blue); $20 \times$ magnification.

Both equol enantiomers prevented HIV-1 Tat-induced $(50 \mathrm{nM})$ and HIV-1 Tat $(10 \mathrm{nM})+$ cocaine induced synaptic loss. TMX pre-treatment blocked the neuroprotective actions of both RE and SE, indicating that equol mediated neuroprotection was via an estrogen receptor dependent mechanism. SE is a potent ER agonist, with preferential binding to $\operatorname{ER} \beta$ over $\operatorname{ER} \alpha$ (Setchell et al., 2005; Lampe, 2009; Jackson et al., 2011). In order to determine the mechanism of both S- and RE synaptic protection, the compounds MPP, PHTPP, and G15 (ER $\alpha, \mathrm{ER} \beta$, and GPR30 antagonists, respectively) were used to determine which ER subtype mediated the neuroprotective effects of SE and RE. Only PHTPP blocked the neuroprotective effects of SE and $\mathrm{RE}$, indicating that both enantiomers provide synaptic protection via an $\operatorname{ER} \beta$ dependent mechanism.

Our prior studies have found that treatment with $17 \beta$-estradiol mitigates interactions between HIV-1 Tat protein and cocaine, thereby preventing neuronal cell death in an ER dependent manner (Kendall et al., 2005). Treatment with 17 $\beta$-estradiol suppresses HIV-1 Tat enhancement of LTR promoter activity in astrocytes (Wilson et al., 2006). Over expression of ER $\alpha$ prevents $17 \beta$-estradiol mediated suppression of Tat-LTR promoter activity in astrocytes (Heron et al., 2009). Unfortunately, activation of the ER $\alpha$ subtype may lead to unwanted side effects, limiting the use of specific agonists which act at $\mathrm{ER} \alpha$ receptors. We reported estrogenic activation of the ER $\beta$ prevented HIV-1 Tat-induced apoptosis (Adams et al., 2010, 2012), and the present findings suggest ER $\beta$ is necessary for synaptic protection following HIV1 Tat and cocaine. Thus, an ER $\beta$ specific compound (i.e., SE or other compounds), may be beneficial for both preventing HIV-1 synaptopathy, although the functional consequences of $\mathrm{ER} \beta$ specific compounds in HIV-1 therapeutics remains to be determined. 
The gut-brain axis is a new area of study which recognizes the bidirectional communication between the gut microbiota and behavior (Cryan and Dinan, 2012; Foster and McVey Neufeld, 2013). SE is produced by the gut microbiota in humans and animals, but not all humans are SE producers. Up to $80 \%$ of individuals in China, Japan, and Korea are capable of producing SE (Morton et al., 2002; Fujimoto et al., 2008), however, only 25\% of the population that consumes a Western diet are SE producers (Lampe et al., 1998). It is currently unknown how HIV-1 may affect the gut microbiota, however, it may play an important role in mediating disease progression as well as the neurocognitive correlates of HIV-1. The ability of the gut metabolite SE to alter the synaptopathy induced either by HIV-1 Tat alone, or HIV-1 Tat and cocaine in combination, suggests that the gut microbiota could play an important role in modulating CNS health in HIV-1.

HIV-1 protein Tat in combination with cocaine resulted in significant loss of synapses; loss which may play a role in the increased prevalence of HAND in cocaine users (Nath, 2010; Purohit et al., 2011). Cognitive function in HAND is closely correlated with synaptodendritic injury (Ellis et al., 2007), and a reduction in synapses represents a potential mechanism for the increased prevalence of HAND in HIV-1+ cocaine users (Martin-Thormeyer and Paul, 2009; Nath, 2010; Gill and Kolson, 2014). HIV-1 Tat + cocaine synaptopathy occurs prior to overt

\section{References}

Adams, S. M., Aksenova, M. V., Aksenov, M. Y., Mactutus, C. F., and Booze, R. M. (2010). ER-beta mediates 17beta-estradiol attenuation of HIV-1 Tat-induced apoptotic signaling. Synapse 64, 829-838. doi: 10.1002/syn.20793

Adams, S. M., Aksenova, M. V., Aksenov, M. Y., Mactutus, C. F., and Booze, R. M. (2012). Soy isoflavones genistein and daidzein exert anti-apoptotic actions via a selective er-mediated mechanism in neurons following hiv-1 tat(1-86) exposure. PLoS ONE 7:e37540. doi: 10.1371/journal.pone.0037540

Aksenov, M. Y., Aksenova, M. V., Nath, A., Ray, P. D., Mactutus, C. F., and Booze, R. M. (2006). Cocaine-mediated enhancement of Tat toxicity in rat hippocampal cell cultures: the role of oxidative stress and D1 dopamine receptor. Neurotoxicology 27, 217-228. doi: 10.1016/j.neuro.2005.10.003

Aksenov, M. Y., Aksenova, M. V., Silvers, J. M., Mactutus, C. F., and Booze, R. M. (2008). Different effects of selective dopamine uptake inhibitors, GBR 12909 and WIN 35428 on HIV-1 Tat toxicity in rat fetal midbrain neurons. Neurotoxicolgy 29, 971-977. doi: 10.1016/j.neuro.2008.06.003

Aksenova, M. V., Aksenov, M. Y., Adams, S. M., Mactutus, C. F., and Booze, R. M. (2009). Neuronal survival and resistance to HIV-1 Tat toxicity in the primary culture of rat fetal neurons. Exp. Neurol. 215, 253-263. doi: 10.1016/j.expneurol.2008.10.006

Aksenova, M. V., Silvers, J. M., Aksenov, M. Y., Nath, A., Ray, P. D., Mactutus, C. F., et al. (2006). HIV-1 Tat neurotoxicity in primary cultures of rat midbrain fetal neurons: changes in dopamine transporter binding and immunoreactivity. Neurosci. Lett. 395, 235-239. doi: 10.1016/j.neulet.2005.10.095

Baum, M. K., Rafie, C., Lai, S., Sales, S., Page, B., and Campa, A. (2009). Crack-cocaine use accelerates HIV disease progression in a cohort of HIV-positive drug users. J. Acquir. Immune Defic. Syndr. 50, 93-99. doi: 10.1097/QAI.0b013e3181900129

Bennett, B., Hyde, C., Peccora, J., and Clodfelter, J. (1993). Long-term cocaine administration is not neurotoxic to cultured fetal mesencephalic dopamine neurons. Neurosci. Lett. 153, 210-214. doi: 10.1016/0304-3940(93) 90324-E

Bertrand, S. J., Aksenova, M. V., Aksenov, M. Y., Mactutus, C. F., and Booze, R. M. (2011). Endogenous amyloidogenesis in long-term rat hippocampal cell cultures. BMC Neurosci. 12:38. doi: 10.1186/1471-2202-12-38 neuronal death (Kim et al., 2008; Bertrand et al., 2013, 2014), and the synaptopathy is potentially reversible (Bertrand et al., 2014), highlighting the importance of compounds, like SE, that may offer synaptic protection and restoration of normal synaptic connectivity. Interestingly, we found that the synaptic protective actions of equol may be mediated by an ER $\beta$-dependent mechanism. Equol actions targeted to the ER $\beta$ may limit unwanted side-effects, yet still provide neuroprotection at a level similar to the effects of $17 \beta$-estradiol (Kendall et al., 2005; Simpkins and Singh, 2008; Adams et al., 2010; Simpkins et al., 2012). SE is more potent than the parent compound daidzein (Adams et al., 2012; Bertrand et al., 2014), suggesting that either direct treatment with SE or treatment via gut metabolism of daidzein may promote synaptic complexity following HIV-1 Tat or Tat + cocaine exposure. Overall, the present data suggest that ER $\beta$ may be a novel therapeutic target for the treatment of HAND + drug abuse synaptopathy and early therapeutic intervention with SE may prevent HIV-1 synaptopathy and potentially delay the development of HAND.

\section{Acknowledgment}

This work was supported by NIH Grant \# DA013137, DA031604, HD043680.

Bertrand, S. J., Aksenova, M. V., Mactutus, C. F., and Booze, R. M. (2013). HIV-1 Tat protein variants: critical role for the cysteine region in synaptodendritic injury. Exp. Neurol. 248, 228-235. doi: 10.1016/j.expneurol.2013. 06.020

Bertrand, S. J., Mactutus, C. F., Aksenova, M. V., Espensen-Sturges, T. D., and Booze, R. M. (2014). Synaptodendritic recovery following HIV Tat exposure: neurorestoration by phytoestrogens. J. Neurochem. 128, 140-151. doi: 10.1111/jnc. 12375

Booze, R. M., Lehner, A. F., Wallace, D. R., Welch, M. A., and Booze, R. M. (1997). Dose-response cocaine pharmacokinetics and metabolite profile following intravenous administration and arterial sampling in unanesthetized, freely moving male rats. Neurotoxicol. Teratol. 19, 7-15. doi: 10.1016/S08920362(96)00180-8

Chang, L., Wang, G. J., Volkow, N. D., Ernst, T., Telang, F., Logan, J., et al. (2008). Decreased brain dopamine transporters are related to cognitive deficits in HIV patients with or without cocaine abuse. Neuroimage 42, 869-878. doi: 10.1016/j.neuroimage.2008.05.011

Cook, J. A., Grey, D. D., Burke-Miller, J. K., Cohen, M. H., Vlahov, D., Kapadia, F., et al. (2007). Illicit drug use, depression and their association with highly active antiretroviral therapy in HIV-positive women. Drug Alcohol Depend. 89, 74-81. doi: 10.1016/j.drugalcdep.2006.12.002

Cryan, J. F., and Dinan, T. G. (2012). Mind-altering microorganisms: the impact of the gut microbiota on brain and behaviour. Nat. Rev. Neurosci. 13, 701-712. doi: $10.1038 / \mathrm{nrn} 3346$

Desplats, P., Dumaop, W., Smith, D., Adame, A., Everall, I., Letendre, S., et al. (2013). Molecular and pathologic insights from latent HIV-1 infection in the human brain. Neurology 80, 1415-1423. doi: 10.1212/WNL.0b013e31828 c2e9e

Devlin, K. N., Gongvatana, A., Clark, U. S., Chasman, J. D., Westbrook, M. L., Tashima, K. T., et al. (2012). Neurocognitive effects of HIV, hepatitis C, and substance use history. J. Int. Neuropsychol. Soc. 18, 68-78. doi: $10.1017 /$ S1355617711001408

Doshi, R. K., Vogenthaler, N. S., Lewis, S., Rodriguez, A., Metsch, L., and del, R. C. (2012). Correlates of antiretroviral utilization among hospitalized HIVinfected crack cocaine users. AIDS Res. Hum. Retrovir. 28, 1007-1014. doi: 10.1089/aid.2011.0329 
Ellis, R., Langford, D., and Masliah, E. (2007). HIV and antiretroviral therapy in the brain: neuronal injury and repair. Nat. Rev. Neurosci. 8, 33-44. doi: $10.1038 / \mathrm{nrn} 2040$

Evans, S. M., Cone, E. J., and Henningfield, J. E. (1996). Arterial and venous cocaine plasma concentrations in humans: relationship to route of administration, cardiovascular effects and subjective effects. J. Pharmacol. Exp. Ther. 279, 1345-1356.

Ferris, M. J., Frederick-Duus, D., Fadel, J., Mactutus, C. F., and Booze, R. M. (2009). The human immunodeficiency virus-1-associated protein, Tat1-86, impairs dopamine transporters and interacts with cocaine to reduce nerve terminal function: a no-net-flux microdialysis study. Neuroscience 159, 1292-1299. doi: 10.1016/j.neuroscience.2009.01.024

Fitting, S., Booze, R. M., and Mactutus, C. F. (2015). HIV proteins, Tat and gp120, target the developing dopamine system. Curr. HIV Res. 13, 21-42. doi: 10.2174/1570162X13666150121110731

Foster, J. A., and McVey Neufeld, K. A. (2013). Gut-brain axis: how the microbiome influences anxiety and depression. Trends Neurosci. 36, 305-312. doi: 10.1016/j.tins.2013.01.005

Fujimoto, K., Tanaka, M., Hirao, Y., Nagata, Y., Mori, M., Miyanaga, N., et al. (2008). Age-stratified serum levels of isoflavones and proportion of equol producers in Japanese and Korean healthy men. Prostate Cancer Prostatic. Dis. 11, 252-257. doi: 10.1038/sj.pcan.4501030

Gill, A. J., and Kolson, D. L. (2014). Chronic inflammation and the role for cofactors (hepatitis C, drug abuse, antiretroviral drug toxicity, aging) in HAND persistence. Curr. HIV/AIDS Rep. 11, 325-335. doi: 10.1007/s11904-014-0210-3

Glazier, M. G., and Bowman, M. A. (2001). A review of the evidence for the use of phytoestrogens as a replacement for traditional estrogen replacement therapy. Arch. Intern. Med. 161, 1161-1172. doi: 10.1001/archinte.161.9.1161

Gongvatana, A., Cohen, R. A., Correia, S., Devlin, K. N., Miles, J., Kang, H., et al. (2011). Clinical contributors to cerebral white matter integrity in HIV-infected individuals. J. Neurovirol. 17, 477-486. doi: 10.1007/s13365-011-0055-0

Halpain, S. (2003). Actin in a supporting role. Nat. Neurosci. 6, 101-102. doi: 10.1038/nn0203-101

Heller, E. A., Zhang, W., Selimi, F., Earnheart, J. C., Slimak, M. A., Santos-Torres, J., et al. (2012). The biochemical anatomy of cortical inhibitory synapses. PLoS ONE 7:e39572. doi: 10.1371/journal.pone.0039572

Heron, P. M., Turchan-Cholewo, J., Bruce-Keller, A. J., and Wilson, M. E. (2009). Estrogen receptor alpha inhibits the estrogen-mediated suppression of HIV transcription in astrocytes: implications for estrogen neuroprotection in HIV dementia. AIDS Res. Hum. Retrovir. 25, 1071-1081. doi: 10.1089/aid.200 9.0065

Hotulainen, P., Llano, O., Smirnov, S., Tanhuanpaa, K., Faix, J., Rivera, C., et al. (2009). Defining mechanisms of actin polymerization and depolymerization during dendritic spine morphogenesis. J. Cell Biol. 185, 323-339. doi: $10.1083 /$ jcb. 200809046

Jackson, R. L., Greiwe, J. S., and Schwen, R. J. (2011). Emerging evidence of the health benefits of S-equol, an estrogen receptor beta agonist. Nutr. Rev. 69, 432-448. doi: 10.1111/j.1753-4887.2011.00400.x

Johnson, O. L., and Ouimet, C. C. (2006). A regulatory role for actin in dendritic spine proliferation. Brain Res. 1113, 1-9. doi: 10.1016/j.brainres.2006.06.116

Kalivas, P. W. (2009). The glutamate homeostasis hypothesis of addiction. Nat. Rev. Neurosci. 10, 561-572. doi: 10.1038/nrn2515

Kendall, S. L., Anderson, C. F., Nath, A., Turchan-Cholewo, J., Land, C. L., Mactutus, C. F., et al. (2005). Gonadal steroids differentially modulate neurotoxicity of HIV and cocaine: testosterone and ICI 182,780 sensitive mechanism. BMC. Neurosci. 6:40. doi: 10.1186/1471-2202-6-40

Kim, H. J., Martemyanov, K. A., and Thayer, S. A. (2008). Human immunodeficiency virus protein Tat induces synapse loss via a reversible process that is distinct from cell death. J. Neurosci. 28, 12604-12613. doi: 10.1523/JNEUROSCI.2958-08.2008

Korthuis, P. T., Zephyrin, L. C., Fleishman, J. A., Saha, S., Josephs, J. S., McGrath, M. M., et al. (2008). Health-related quality of life in HIV-infected patients: the role of substance use. AIDS Patient. Care STDS 22, 859-867. doi: 10.1089/apc.2008.0005

Krogh, K. A., Lyddon, E., and Thayer, S. A. (2015). HIV-1 Tat activates a RhoA signaling pathway to reduce NMDA-evoked calcium responses in hippocampal neurons via an actin-dependent mechanism. J. Neurochem. 132, 354-366. doi: $10.1111 /$ jnc. 12936
Kurapati, K. R., Atluri, V. S., Samikkannu, T., and Nair, M. P. (2013). Ashwagandha (Withania somnifera) reverses beta-amyloid1-42 induced toxicity in human neuronal cells: implications in HIV-1 associated neurocognitive disorders (HAND). PLoS ONE 8:e77624. doi: 10.1371/journal.pone.0077624

Kurapati, K. R., Samikkannu, T., Atluri, V. S., Kaftanovskaya, E., Yndart, A., and Nair, M. P. (2014). Beta-amyloid 1-42, HIV-1b (Clade B) infection and drugs of abuse induced degeneration in human neuronal cells and protective effects of Ashwagandha (Withania somnifera) and its constituent Withanolide A. PLoS ONE 9:e112818. doi: 10.1371/journal.pone.0112818

Lampe, J. W. (2009). Is equol the key to the efficacy of soy foods? Am. J. Clin. Nutr. 89, 1664S-1667S. doi: 10.3945/ajcn.2009.26736T

Lampe, J. W., Karr, S. C., Hutchins, A. M., and Slavin, J. L. (1998). Urinary equol excretion with a soy challenge: influence of habitual diet. Proc. Soc. Exp. Biol. Med. 217, 335-339. doi: 10.3181/00379727-217-44241

Lephart, E. D., Setchell, K. D., and Lund, T. D. (2005). Phytoestrogens: hormonal action and brain plasticity. Brain Res. Bull. 65, 193-198. doi: 10.1016/j.brainresbull.2004.11.022

Levine, A. J., Hardy, D. J., Miller, E., Castellon, S. A., Longshore, D., and Hinkin, C. H. (2006). The effect of recent stimulant use on sustained attention in HIV-infected adults. J. Clin. Exp. Neuropsychol. 28, 29-42. doi: $10.1080 / 13803390490918066$

Li, H., Aksenova, M. V., Bertrand, S. J., Mactutus, C. F., and Booze, R. M. (2015). Quantification of filamentous actin (F-actin) puncta in rat cortical neurons. J. Vis. Exp. (in press).

Li, W., Galey, D., Mattson, M. P., and Nath, A. (2005). Molecular and cellular mechanisms of neuronal cell death in HIV dementia. Neurotox. Res. 8, 119-134. doi: 10.1007/BF03033824

Mactutus, C. F., Herman, A., and Booze, R. M. (1994). Chronic intravenous model for studies of drug abuse in the preganant and/or group-housed rat: an initial study with cocaine. Neurotoxicol. Teratol. 16, 183-191. doi: 10.1016/08920362(94)90116-3

Martin, B. J., Naughton, B. J., Thirtamara-Rajamani, K., Yoon, D. J., Han, D. D., Devries, A. C., et al. (2011). Dopamine transporter inhibition is necessary for cocaine-induced increases in dendritic spine density in the nucleus accumbens. Synapse 65, 490-496. doi: 10.1002/syn.20865

Martin-Thormeyer, E. M., and Paul, R. H. (2009). Drug abuse and hepatitis C infection as comorbid features of HIV associated neurocognitive disorder: neurocognitive and neuroimaging features. Neuropsychol. Rev. 19, 215-231. doi: 10.1007/s11065-009-9101-6

Mattson, M. P., Haughey, N. J., and Nath, A. (2005). Cell death in HIV dementia. Cell Death. Differ. 12(Suppl. 1), 893-904. doi: 10.1038/sj.cdd.4401577

Matus, A., Ackermann, M., Pehling, G., Byers, H. R., and Fujiwara, K. (1982). High actin concentrations in brain dendritic spines and postsynaptic densities. Proc. Natl. Acad. Sci. U.S.A. 79, 7590-7594. doi: 10.1073/pnas.79.23.7590

Midde, N. M., Huang, X., Gomez, A. M., Booze, R. M., Zhan, C. G., and Zhu, J. (2013). Mutation of tyrosine 470 of human dopamine transporter is critical for HIV-1 Tat-induced inhibition of dopamine transport and transporter conformational transitions. J. Neuroimmune Pharmacol. 8, 975-987. doi: 10.1007/s11481-013-9464-6

Moore, D. J., Masliah, E., Rippeth, J. D., Gonzalez, R., Carey, C. L., Cherner, M., et al. (2006). Cortical and subcortical neurodegeneration is associated with HIV neurocognitive impairment. AIDS 20, 879-887. doi: 10.1097/01.aids.0000218552.69834.00

Morton, M. S., Arisaka, O., Miyake, N., Morgan, L. D., and Evans, B. A. (2002). Phytoestrogen concentrations in serum from Japanese men and women over forty years of age. J. Nutr. 132, 3168-3171.

Nassogne, M. C., Evrard, P., and Courtoy, P. J. (1995). Selective neuronal toxicity of cocaine in embryonic mouse brain cocultures. Proc. Natl. Acad. Sci. U.S.A. 92, 11029-11033. doi: 10.1073/pnas.92.24.11029

Nath, A. (2002). Human immunodeficiency virus (HIV) proteins in neuropathogenesis of HIV dementia. J. Infect. Dis. 186(Suppl. 2), S193-S198. doi: $10.1086 / 344528$

Nath, A. (2010). Human immunodeficiency virus-associated neurocognitive disorder: pathophysiology in relation to drug addiction. Ann. N. Y. Acad. Sci. 1187, 122-128. doi: 10.1111/j.1749-6632.2009.05277.x

Ortega, M., Brier, M. R., and Ances, B. M. (2015). Effects of HIV and combination antiretroviral therapy on cortico-striatal functional connectivity. AIDS 29, 703-712. doi: 10.1097/QAD.0000000000000611 
Panos, S. E., Del Re, A. C., Thames, A. D., Arentsen, T. J., Patel, S. M., Castellon, S. A., et al. (2014). The impact of neurobehavioral features on medication adherence in HIV: evidence from longitudinal models. AIDS Care 26, 79-86. doi: 10.1080/09540121.2013.802275

Patisaul, H. B., Todd, K. L., Mickens, J. A., and Adewale, H. B. (2009). Impact of neonatal exposure to the ERalpha agonist PPT, bisphenol-A or phytoestrogens on hypothalamic kisspeptin fiber density in male and female rats. Neurotoxicology 30, 350-357. doi: 10.1016/j.neuro.2009.02.010

Purohit, V., Rapaka, R., and Shurtleff, D. (2011). Drugs of abuse, dopamine, and HIV-associated neurocognitive disorders/HIV-associated dementia. Mol. Neurobiol. 44, 102-110. doi: 10.1007/s12035-011-8195-Z

Qian, H. Z., Mitchell, V. J., Bebawy, S., Cassell, H., Perez, G., McGowan, C. C., et al. (2014). Current drug use and lack of HIV virologic suppression: pointof-care urine drug screen versus self-report. BMC Infect. Dis. 14:508. doi: 10.1186/1471-2334-14-508

Ritz, M. C., and Kuhar, M. J. (1993). Psychostimulant drugs and a dopamine hypothesis regarding addiction: update on recent research. Biochem. Soc. Symp. 59, 51-64.

Roscoe, R. F. Jr., Mactutus, C. F., and Booze, R. M. (2014). HIV-1 transgenic female rat: synaptodendritic alterations of medium spiny neurons in the nucleus accumbens. J. Neuroimmune Pharmacol. 9, 642-653. doi: 10.1007/s11481-0149555-Z

Sankaranarayanan, S., Atluri, P. P., and Ryan, T. A. (2003). Actin has a molecular scaffolding, not propulsive, role in presynaptic function. Nat. Neurosci. 6, 127-135. doi: 10.1038/nn1002

Sekino, Y., Kojima, N., and Shirao, T. (2007). Role of actin cytoskeleton in dendritic spine morphogenesis. Neurochem. Int. 51, 92-104. doi: 10.1016/j.neuint.2007.04.029

Setchell, K. D., and Cassidy, A. (1999). Dietary isoflavones: biological effects and relevance to human health. J. Nutr. 129, 758S-767S.

Setchell, K. D., Clerici, C., Lephart, E. D., Cole, S. J., Heenan, C., Castellani, D., et al. (2005). S-equol, a potent ligand for estrogen receptor beta, is the exclusive enantiomeric form of the soy isoflavone metabolite produced by human intestinal bacterial flora. Am. J. Clin. Nutr. 81, 1072-1079.

Simpkins, J. W., and Singh, M. (2008). More than a decade of estrogen neuroprotection. Alzheimers. Dement. 4, S131-S136. doi: 10.1016/j.jalz.2007.10.009

Simpkins, J. W., Singh, M., Brock, C., and Etgen, A. M. (2012). Neuroprotection and Estrogen Receptors. Neuroendocrinology 96, 119-130. doi: $10.1159 / 000338409$
Toda, S., Shen, H., and Kalivas, P. W. (2010). Inhibition of actin polymerization prevents cocaine-induced changes in spine morphology in the nucleus accumbens. Neurotox. Res. 18, 410-415. doi: 10.1007/s12640-010 9193-Z

Wallace, D. R., Dodson, S., Nath A., and Booze, R. M. (2006). Estrogen attenuates gp120- and tat1-72-induced oxidative stress and prevents loss of dopamine transporter function. Synapse 59, 51-60. doi: 10.1002/syn.20214

Weber, E., Morgan, E. E., Iudicello, J. E., Blackstone, K., Grant, I., Ellis, R. J., et al. (2013). Substance use is a risk factor for neurocognitive deficits and neuropsychiatric distress in acute and early HIV infection. J. Neurovirol. 19, 65-74. doi: 10.1007/s13365-012-0141-y

Wilson, M. E., Allred, K. F., Bisotti, A. J., Bruce-Keller, A., Chuahan, A., and Nath, A. (2006). Estradiol negatively regulates HIV-LTR promoter activity in glial cells. AIDS Res. Hum. Retrovir. 22, 350-356. doi: 10.1089/aid.2006.22.350

Wisniewski, A. B., Apel, S., Selnes, O. A., Nath, A., McArthur, J. C., and Dobs, A. S. (2005). Depressive symptoms, quality of life, and neuropsychological performance in HIV/AIDS: the impact of gender and injection drug use. J. Neurovirol. 11, 138-143. doi: 10.1080/13550280590922748

Wu, R. F., Gu, Y., Xu, Y. C., Mitola, S., Bussolino, F., and Terada, L. S. (2004). Human immunodeficiency virus type 1 Tat regulates endothelial cell actin cytoskeletal dynamics through PAK1 activation and oxidant production. J. Virol. 78, 779-789. doi: 10.1128/JVI.78.2.779-789.2004

Yao, J., Zhao, L., Mao, Z., Chen, S., Wong, K. C., To, J., et al. (2013) Potentiation of brain mitochondrial function by $\mathrm{S}$-equol and R/S-equol estrogen receptor beta-selective phytoSERM treatments. Brain Res. 1514, 128-141. doi: 10.1016/j.brainres.2013.02.021

Zhang, W., and Benson, D. L. (2001). Stages of synapse development defined by dependence on F-actin. J. Neurosci. 21, 5169-5181.

Conflict of Interest Statement: The authors declare that the research was conducted in the absence of any commercial or financial relationships that could be construed as a potential conflict of interest.

Copyright (c) 2015 Bertrand, Hu, Aksenova, Mactutus and Booze. This is an openaccess article distributed under the terms of the Creative Commons Attribution License (CC BY). The use, distribution or reproduction in other forums is permitted, provided the original author(s) or licensor are credited and that the original publication in this journal is cited, in accordance with accepted academic practice. No use, distribution or reproduction is permitted which does not comply with these terms. 